\title{
Isoniazid-Induced Facial Tics in a Patient on Hemodialysis
}

\author{
Yuanwei Wang ${ }^{*}$, Xiaodong Chen ${ }^{1}$, Xiaomei Li², Baolin Zhu' ${ }^{1}$, Daoming Tong1 \\ ${ }^{1}$ Department of Neurology, the People's Hospital of Shuyang, Shuyang, China \\ ${ }^{2}$ Centers for Disease Control and Prevention of Binzhou City, Binzhou, China \\ Email: *wyweilmn@126.com
}

How to cite this paper: Wang, Y.W., Chen, X.D., Li, X.M., Zhu, B.L. and Tong, D.M. (2017) Isoniazid-Induced Facial Tics in a Patient on Hemodialysis. Neuroscience \& Medicine, 8, 25-28. https://doi.org/10.4236/nm.2017.83003

Received: May 16, 2017

Accepted: August 21, 2017

Published: August 24, 2017

Copyright (c) 2017 by authors and Scientific Research Publishing Inc. This work is licensed under the Creative Commons Attribution International License (CC BY 4.0).

http://creativecommons.org/licenses/by/4.0/

\begin{abstract}
We report isoniazid (INH) induced tics in one male patient on hemodialysis at end-stage renal failure. He had pulmonary tuberculosis, accepted isoniazid, rifampin, ethambutol, pyrazinamide and rifampicin. He developed tics on both sides of the face. Surprisingly, he was also found the bilateral symmetrical frontal lobe and dentate nucleus hyperintensities on T2-weighted and T2 FLAIR MR imaging. After excluding other causes, INH induced neurological side effect was suspected so the drug was stopped, pyridoxine was added and hemoperfusion was applicated. Tics disappeared after 1 week.
\end{abstract}

\section{Keywords}

Tic, Isoniazid, Tuberculosis, ESRD, Hemodialysis

\section{Introduction}

$\mathrm{INH}$ is a first-line drug for anti-tuberculosis, and the therapeutic dose rarely causes adverse reactions. However, many scholars had found when there was excessive smoking, drinking or renal failure, the therapeutic dose of INH was easy to cause the central nervous system toxicity [1] [2]. So we report one case of INH induced facial tics at therapeutic dose.

\section{Case}

A 57-year-old male Patient was admitted with acute left ventricular failure in the department of Medicine. The patient was a known case of end stage renal failure (ESRD) secondary to diabetic nephropathy and hypertension, and was on regular hemodialysis three times per week for the last one year. He was diagnosed as pulmonary tuberculosis 3 months before this admission, and was treated with 
multiple anti-tuberculosis drugs including INH $300 \mathrm{mg} /$ day, ethambutol 0.75 $\mathrm{g} /$ day, pyrazinamide $1.5 \mathrm{~g} /$ day and rifampicin $0.9 \mathrm{~g} /$ day. On the night at 10 days after admission, the patients presented self-uncontrolled bilateral facial tics without obviously causes, the drugs (diazepam $10 \mathrm{mg}$ prn, luminal sodium 0.1 im bid) were then added to prevent the tics but no obviously improvement.

On examination, the patient was conscious. He presented with bad mental state, severe anemia countenance and severe pitting edema on his double lower

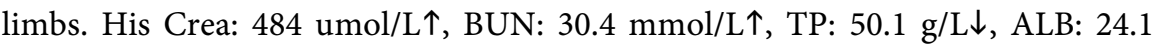
g/L $\downarrow$, RBC: $2.37 \times 10^{12} \downarrow, \beta 2$-MG: $30.49 \mathrm{mg} / \mathrm{L} \uparrow$, HGB: $57 \mathrm{~g} / \mathrm{L} \downarrow$ were remarkable in biochemistry and blood routine test. The magnetic radio imaging of the brain (Figure 1) showed multiple abnormal signal in the bilateral lateral ventricle, frontal lobe and cerebellar dentate nuclei, but no necrotic lesion was found, the vascular and organic neurological causes were excluded, an INH toxicity to brain was suspected (the serum level of INH was not determined in our laboratory). Then the INH was stopped and pyridoxine in a dose of $80 \mathrm{mg} /$ day was administered. After 4 days, the symptom was improved significantly and INH was re-added to anti-tuberculosis therapy in a lower dose of $200 \mathrm{mg} /$ day. On day 7 after the adjustment of anti-tuberculosis therapy, the tics disappeared completely.

\section{Discussion}

It is reported that patients with end stage renal disease have a high incidence of tuberculosis, as well as increased incidence of side effects secondary to anti-tuberculosis agent in treatment of anti-tuberculosis in patient with ESRD [3]. The mechanism maybe associated with increasing of serum concentration of anti-

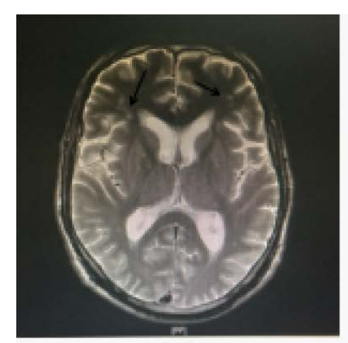

(a)

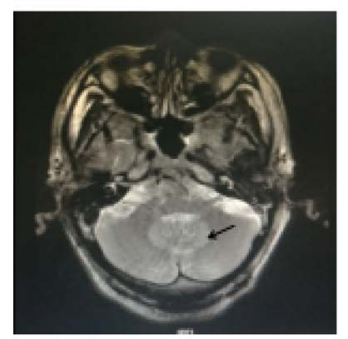

(d)

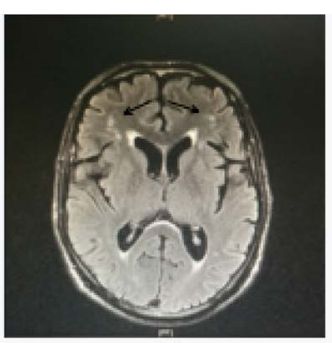

(b)

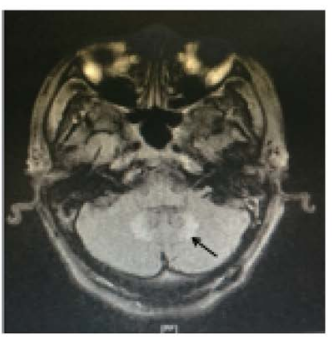

(e)

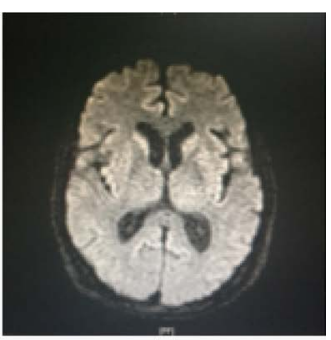

(c)

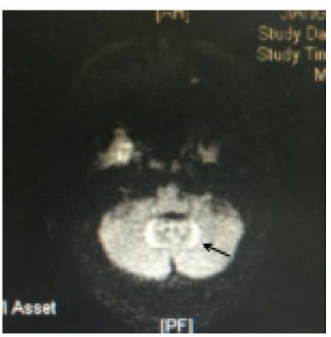

(f)

Figure 1. (a)-(c) Axial T2 and T2 FLAIR MR image shows symmetrical hyperintensities involving the frontal lobe (arrows) diffusion-weighted MR image shows nothing; (d)-(f) Axial T2, T2 FLAIR and diffusion-weighted MR image shows symmetrical hyperintensities involving the bilateral dentate nuclei (arrows). 
tuberculosis agents, decreasing of serum proteins and increasing of bioavailability of these agents [4].

As the first-line drugs for treatment of tuberculosis, INH is well known to have more neurological side effects. Such as headache, insomnia, fatigue, memory loss, illusion, convulsions, and facial tics may be the first reported in cases with ESRD on hemodialysis. It is reported that the neurological side effects of INH is associated with its metabolism style and the ability of competing with pyridoxine [5].

Those with slow acetylation metabolize INH more slowly than others with fast acetylation, and therefore have higher serum level of INH, which produce more side effects. In addition, the ability of crossing the blood-brain barrier produces higher level of INH in brain [6]. In this reported case, vitamin B6 was not administered until the tics occurred, which may be an import reason causing neurotoxic syndrome. Also, when there was renal dysfunction, the excretion of INH decreased, leading to increased concentration, and low serum albumin, high concentration of creatinine, and urea nitrogen would increase the permeability of blood brain barrier to INH. Meanwhile, INH may inhibit the utilization of pyridoxine, when pyridoxine deficiency, GABA production decreased, leading to excitement, restlessness, and even tics [5] [7].

Prasant Peter [8] reported that isolated bilateral symmetrical dentate nucleus hyperintensities on T2-weighted and T2 FLAIR MR imaging in a patient with neurological side effects secondary to INH. In this case, we also found the bilateral symmetrical frontal lobe hyperintensities MR imaging. In the present case, all these differentials were ruled out based on the patient's medical history and the results of clinical investigations. Therefore, we concluded that the unusual imaging presentations were a result of INH neurotoxicity.

Another particularly aspect noticed was symptoms and Imaging findings showed in the reported case was not concordance. This indicated damage was greater than Imaging findings.

\section{Conclusion}

In conclusion, the possibility of facial tics secondary to INH neurotoxicity should be considered in patients on hemodialysis who undergo anti-tuberculosis treatment. In order to prevent the neurotoxicity associated with INH therapy, treatment with high-dose pyridoxine should be initiated. INH should also be withheld if symptoms of neurotoxicity don't stop or develop. When the patient has renal insufficiency and low immunity, the dose of isoniazid should be reduced.

\section{Acknowledgements}

The authors thank Dr. Baoguang Hu for his support in the development of this article.

\section{Disclosure}

The authors have reported no conflicts of interest. The patients had given their 
consent for the case reports to be published.

\section{References}

[1] Aiwale, A.S., Patel, U.A., Barvaliya, M.J., Jha, P.R. and Tripathi, C. (2015) Isoniazid Induced Convulsions at Therapeutic Dose in an Alcoholic and Smoker Patient. Current Drug Safety, 10, 94-95. https://doi.org/10.2174/1574886309666140930151343

[2] Tsubouchi, K., Ikematsu, Y., Hashisako, M., Harada, E., Miyagi, H. and Fujisawa, N. (2014) Convulsive Seizures with a Therapeutic Dose of Isoniazid. Internal Medicine, 53, 239-242.

[3] Shu, C.C., Hsu, C.L., Lee, C.Y., Wang, J.Y., Wu, V.C., Yang, F.J., Wang, J.T., Yu, C.J. and Lee, L.N. (2015) Comparison of the Prevalence of Latent Tuberculosis Infection among Non-Dialysis Patients with Severe Chronic Kidney Disease, Patients Receiving Dialysis, and the Dialysis-Unit Staff: A Cross-Sectional Study. PLoS ONE, 10, e0124104. https://doi.org/10.1371/journal.pone.0124104

[4] Manian, F.A., Stone, W.J. and Alford, R.H. (1990) Adverse Antibiotic Effects Associated with Renal Insufficiency. Reviews of Infectious Diseases, 12, 236-249. https://doi.org/10.1093/clinids/12.2.236

[5] Bhattacharyya, S., Darby, R.R., Raibagkar, P., Gonzalez Castro, L.N. and Berkowitz, A.L. (2016) Antibiotic-Associated Encephalopathy. Neurology, 86, 963-971.

[6] Nau, R., Sorgel, F. and Eiffert, H. (2010) Penetration of Drugs through the Blood-Cerebrospinal Fluid/Blood-Brain Barrier for Treatment of Central Nervous System Infections. Clinical Microbiology Reviews, 23, 858-883.

[7] Minns, A.B., Ghafouri, N. and Clark, R.F. (2010) Isoniazid-Induced Status Epilepticus in a Pediatric Patient after Inadequate Pyridoxine Therapy. Pediatric Emergency Care, 26, 380-381. https://doi.org/10.1097/PEC.0b013e3181db24b6

[8] Peter, P. and John, M. (2014) Isoniazid-Induced Cerebellitis: A Disguised Presentation. Singapore Medical Journal, 55, e17-e19.

https://doi.org/10.11622/smedj.2013188

\section{Scientific Research Publishing}

Submit or recommend next manuscript to SCIRP and we will provide best service for you:

Accepting pre-submission inquiries through Email, Facebook, LinkedIn, Twitter, etc. A wide selection of journals (inclusive of 9 subjects, more than 200 journals)

Providing 24-hour high-quality service

User-friendly online submission system

Fair and swift peer-review system

Efficient typesetting and proofreading procedure

Display of the result of downloads and visits, as well as the number of cited articles

Maximum dissemination of your research work

Submit your manuscript at: http://papersubmission.scirp.org/

Or contactnm@scirp.org 